CLINICAL STUDY

\title{
Distribution of neuropeptide Y Leu7Pro polymorphism in patients with type 1 diabetes and diabetic nephropathy among Swedish and American populations
}

Jun Ma, Sofia Nordman, Anna Möllsten ${ }^{1}$, Henrik Falhammar, Kerstin Brismar, Gisela Dahlquist ${ }^{1}$, Suad Efendic and Harvest F Gu

Department of Molecular Medicine and Surgery, L6:B2, Karolinska Institutet, Rolf Luft Center for Diabetes Research, Karolinska University Hospital, SE-171 76 Stockholm, Sweden and ${ }^{1}$ Department of Clinical Sciences, Paediatrics, Umeå University, Umeå, Sweden

(Correspondence should be addressed to H F Gu; Email: harvest.gu@ki.se)

\begin{abstract}
Objective: The distribution of Leu7Pro polymorphism in the neuropeptide Y gene shows a geographical north to south gradient of decreasing frequency, suggesting that it may be a population-specific causal variant. This polymorphism is found to be associated with diabetic nephropathy (DN) and coronary heart disease in Finnish women with type 1 diabetes (T1D). The present study aims to evaluate the susceptibility of this polymorphism to the development of DN in two different populations.

Design: One sample set consists of 174 (females 98 and males 76) Swedish T1D patients with DN and 249 (females 132 and males 117) patients withoutDN. Another sample set includes 597 (females 356 and males 241) American T1D patients without DN and 577 (females 264 and males 313) patients with DN, who were descents of European Caucasians and were from the Genetics of Kidneys in Diabetes (GoKinD) Study. Methods: Genotyping of Leu7Pro polymorphism was performed by dynamic allele-specific hybridization. Results: The $\mathrm{C}$ allele frequencies of Leu7Pro polymorphism in T1D patients between Swedish and American GoKinD populations were significantly different ( 6.3 vs $4.0 \% ; P=0.006$ ). Particularly, the $C$ allele frequency in Swedish female T1D patients with DN was significantly higher in comparison with T1D patients without DN (10.2 vs 4.2\%; $P=0.011, \mathrm{OR}=2.614,95 \%$ confidence intervals: $1.249-5.467)$. No significant association of this polymorphism with DN was observed in Swedish male T1D patients and the patients from GoKinD.

Conclusions: The present study provides further evidence that Leu7Pro polymorphism confers the susceptibility to the development of DN in Swedish female T1D patients.
\end{abstract}

European Journal of Endocrinology 157 641-645

\section{Introduction}

The patients with type 1 diabetes (T1D, online Mendelian inheritance in man (OMIM) 222100) often develop serious long-term complications including diabetic nephropathy (DN). DN leads to renal failure and is also associated with a high risk of coronary artery disease and other vascular complications. The development of $\mathrm{DN}$ is influenced by genetic and environmental factors. Thus, identification of the polymorphisms in the susceptibility genes associated with DN could enable earlier detection of these complex diseases. An understanding of the role of the susceptibility genes in DN will ultimately allow the development of novel therapeutic strategies (1).

Neuropeptide Y (NPY, OMIM 162640) is a 36-amino acid polypeptide that is present in the central and peripheral nervous systems, several peripheral organs, and plasma (2-5). Both in vivo and in vitro studies have demonstrated that NPY inhibits glucose-stimulated insulin secretion $(6,7)$. NPY has also been shown to regulate renal blood flow (8). Stimulation of the NPY receptors in the kidney, using active agonists, may decrease glomerular filtration rate, aldosterone concentration, and plasma renin activity, but increase sodium excretion in the kidney (9). A clinical study indicates that plasma immunoreactive (IR)-NPY and urinary IR-NPY concentrations are elevated in type 2 diabetic (T2D) patients with advanced nephropathy (10). Several studies, using T1D animal models such as the streptozotocin-diabetic rats, have demonstrated that NPY release is increased in the hypothalamus $(11,12)$. The evidence implies that NPY may play a role in the pathogenesis of diabetes and DN.

The NPY gene is located in chromosome 7p15.1. There is a unique detectable non-synonymous single nucleotide polymorphism (SNP), i.e. Leu7Pro (T1128C) found in the coding region of the gene (13). The consequence of Pro7 substitution on prepro-NPY is not fully understood, but the Pro7 may have an impact on NPY processing, circulating NPY levels, growth 
hormone secretion, and serum cholesterol and triglyceride levels (13-17). Interestingly, the polymorphism exists with a relatively high frequency in Finnish and Swedish populations but low frequency in other ethnic populations $(18,19)$. In the past 7 years, several genetic studies indicate that polymorphism is associated with the development of T2D (20), retinopathy $(21,22)$, and enhanced carotid atherosclerosis (23). Moreover, there is a report indicating that Leu7Pro polymorphism confers susceptibility to the development of nephropathy and coronary heart disease (CHD) in Finnish female T1D patients (24). In the present study, we have conducted a genetic association analysis of the polymorphism in two populations including Swedish and American T1D patients with or without DN. The aim is to evaluate the susceptibility of NPY Leu7Pro polymorphism to the development of $\mathrm{DN}$ in these two populations.

\section{Design and methods}

\section{Subjects}

The clinical material in the present study consists of two sample sets from Swedish and American populations. All T1D patients were diagnosed according to the World Health Organization criteria (25). The studies were approved by the local ethics committees. Informed consents were obtained from all the subjects studied. Clinical characteristics of the subjects from Swedish and American populations are summarized in Table 1.

The first sample set included 174 (females 98 and males 76) T1D patients with DN and 249 (females 132 and males 117) patients without DN. All patients were Swedish Caucasians. All T1D patients had the urinary albumin excretion rates (UAER) measured. The patients without DN had UAER of $<20 \mu \mathrm{g} / \mathrm{min}$. One hundred
T1D patients with microalbuminuria (incipient nephropathy) had UAER of $20-200 \mu \mathrm{g} / \mathrm{min}$ in at least two out of three consecutive overnight samples. Seventy-four patients with macroalbuminuria (overt nephropathy) had UAER of $>200 \mu \mathrm{g} / \mathrm{min}$ (the cases with end-stage renal disease (ESRD), not due to the condition other than diabetes, were included in the patients with overt nephropathy but the number is limited). The patients with DN had retinopathy as well. Non-diabetic kidney diseases and ESRF were excluded. T1D patients with DN had no treatment using ACE inhibitors.

The second sample set had 597 (females 356 and males 241) American T1D patients without DN and 577 (females 264 and males 313) patients with DN, who were from the Genetics of Kidneys in Diabetes (GoKinD) Study (26). All patients were descents of European Caucasians. The T1D patients were diagnosed before the age of 31 years. Treatment with insulin was instituted within 1 year of diagnosis, and treatment with insulin has been uninterrupted since diagnosis. The patients with DN had persistent proteinuria for at least 10 years or ESRD $(n=408$, not due to the condition other than diabetes). Persistent proteinuria was defined as two out of three tests positive for albuminuria (at least 1 month apart), i.e. dipstick (Albustix or Multistix) at least $1+$ or urine albumin/ urine creatinine ratio (ACR) value exceeding $300 \mu \mathrm{g}$ albumin/mg of urine creatinine. The patients without DN had persistent normoalbuminuria despite duration of T1D for at least 15 years and had never been treated with ACE inhibitors. Persistent normoalbuminuria was defined as at least two out of three ACR measurements (at least 1 month apart) in random urine specimens being $<20 \mu \mathrm{g}$ albumin $/ \mathrm{mg}$ of urine creatinine. If three ACR measurements were needed, the highest must also be $<40 \mu \mathrm{g}$ albumin/mg of urine creatinine. Other kidney diseases in these cases were excluded.

Table 1 Clinical materials.

\begin{tabular}{|c|c|c|c|c|c|c|c|c|c|}
\hline & \multicolumn{3}{|c|}{ T1D without DN } & \multicolumn{3}{|c|}{ T1D with DN } & \multicolumn{3}{|c|}{$P$ values $^{a}$} \\
\hline & All & Male & Female & All & Male & Female & All & Male & Female \\
\hline \multicolumn{10}{|l|}{ Swedish population } \\
\hline$N$ & 249 & 117 & 132 & 174 & 76 & 98 & - & & \\
\hline Age (years) & $44 \pm 12$ & $45 \pm 12$ & $43 \pm 12$ & $45 \pm 12$ & $47 \pm 12$ & $43 \pm 11$ & 0.271 & 0.063 & 0.879 \\
\hline Duration (years) & $30 \pm 10$ & $29 \pm 10$ & $31 \pm 10$ & $34 \pm 12$ & $34 \pm 13$ & $34 \pm 10$ & 0.001 & 0.010 & 0.046 \\
\hline BMI $\left(\mathrm{kg} / \mathrm{m}^{2}\right)$ & $24.6 \pm 3.1$ & $24.9 \pm 2.2$ & $24.4 \pm 3.6$ & $25.7 \pm 3.8$ & $25.6 \pm 3.7$ & $25.9 \pm 3.9$ & 0.080 & 0.100 & 0.041 \\
\hline SBP (mmHg) & $127 \pm 15$ & $129 \pm 14$ & $125 \pm 16$ & $140 \pm 21$ & $141 \pm 24$ & $140 \pm 18$ & $<0.001$ & $<0.001$ & $<0.001$ \\
\hline $\mathrm{DBP}(\mathrm{mmHg})$ & $74 \pm 7$ & $75 \pm 7$ & $72 \pm 7$ & $79 \pm 10$ & $80 \pm 11$ & $79 \pm 10$ & $<0.001$ & 0.003 & $<0.001$ \\
\hline $\mathrm{HbA1c}(\%)$ & $7.0 \pm 1.1$ & $6.9 \pm 1.0$ & $7.2 \pm 1.2$ & $7.4 \pm 1.3$ & $7.1 \pm 1.3$ & $7.6 \pm 1.3$ & 0.014 & 0.189 & 0.035 \\
\hline \multicolumn{10}{|l|}{ GoKinD population } \\
\hline$N(\mathrm{M} / \mathrm{F})$ & 597 & 241 & 356 & 577 & 313 & 264 & - & & \\
\hline Age (years) & $40 \pm 8$ & $40 \pm 8$ & $40 \pm 9$ & $44 \pm 6$ & $45 \pm 6$ & $44 \pm 7$ & $<0.001$ & $<0.001$ & $<0.001$ \\
\hline Duration (years) & $26 \pm 8$ & $26 \pm 8$ & $26 \pm 8$ & $32 \pm 8$ & $32 \pm 8$ & $32 \pm 8$ & $<0.001$ & $<0.001$ & $<0.001$ \\
\hline BMI $\left(\mathrm{kg} / \mathrm{m}^{2}\right)$ & $26.0 \pm 4.4$ & $26.6 \pm 3.7$ & $25.6 \pm 4.7$ & $25.7 \pm 5.3$ & $26.1 \pm 4.8$ & $25.2 \pm 5.7$ & 0.199 & 0.160 & 0.289 \\
\hline $\mathrm{SBP}(\mathrm{mmHg})$ & $118 \pm 12$ & $122 \pm 12$ & $116 \pm 12$ & $131 \pm 19$ & $133 \pm 18$ & $130 \pm 20$ & $<0.001$ & $<0.001$ & $<0.001$ \\
\hline $\mathrm{DBP}(\mathrm{mmHg})$ & $71 \pm 8$ & $74 \pm 8$ & $70 \pm 7$ & $74 \pm 11$ & $75 \pm 11$ & $72 \pm 11$ & $<0.001$ & 0.025 & 0.004 \\
\hline $\mathrm{HbA1c}(\%)$ & $7.5 \pm 1.1$ & $7.4 \pm 1.1$ & $7.5 \pm 1.1$ & $7.4 \pm 1.9$ & $7.4 \pm 1.7$ & $7.4 \pm 2.1$ & 0.312 & 0.981 & 0.241 \\
\hline
\end{tabular}

All data are means \pm s.D. ND, non-diabetic subjects; T1D, type 1 diabetic patients; DN, diabetic nephropathy; ACR, albuminuria/creatinine ratio; SBP, systolic blood pressure; DBP, diastolic blood pressure.

${ }^{2}$ Tests were done between T1D without and with DN in each group, all or male or female respectively. 


\section{PCR-DASH genotyping}

Genomic DNA was extracted from peripheral blood using a Puregene DNA purification kit (Gentra System, Minneapolis, MN, USA). Leu7Pro (T1128C) polymorphism in the NPY gene is recorded and available publicly in dbSNP (rs16139, http://www.ncbi.nlm.nih.gov/SNP/easyform. html) and HGVbase (SNP000003321, http://hgvbase. cgb.ki.se). We used a high-throughput SNP scoring technique called dynamic allele-specific hybridization (DASH). The optimized PCR conditions are the same as in our previous report (20), and also available if required. The PCR-DASH assay for genotyping this SNP included the forward and reverse primers (5'-CGAAGGTCAGTCAGGACAGCCC-3'; 5'-biotin-CTGCAGATTCTAGGTAACAAGC$\left.3^{\prime}\right)$ and probe (5'-GACAGCCCCGGTCGCTTG-Rox-3' or 5'-GACAGCCCCAGTCGCTTG-Rox-3').

\section{Statistical analyses}

Allele frequency and genotype distribution for the studied SNP were tested for Hardy-Weinberg equilibrium. For differences between T1D patients and non-diabetic controls, two models were tested comparing either allele frequencies in $2 \times 2$ contingency tables or genotypes in $3 \times 2$ contingency tables. Tests for association between genotypes and quantitative traits were performed by Kruskal-Wallis analysis of ranks for traits with nonnormal distributions or, alternatively, ANOVA for normally distributed traits. For association estimation, odds ratios (OR) and 95\% confidence intervals (CI) were obtained from unconditional logistic regression model. Bonferroni correction was used for multiple comparisons. The multivariate logistic regression analysis was used to predict the susceptibility to DN between case and control subjects; the basic model included the frequency-matching variables such as duration, $\mathrm{HbA1c}$, systolic, and diastolic blood pressures as potential confounding factors. $P<0.05$ was considered statistically significant. Analyses were carried out using a BioMedical Data Program (BMDP, Cork, Ireland) version 1.12 and/or STATISTICA version 7.0 (Tulsa, USA).

\section{Results}

We have genotyped Leu7Pro polymorphism in the NPY gene in T1D patients with and without DN among Swedish and American populations. Genotype distributions of this polymorphism in both populations were kept in HardyWeinberg equilibrium. The genotype distributions and allele frequencies for Leu7Pro polymorphism in the NPY gene in T1D patients with and/or without DN among Swedish and American populations are summarized in Table 2. In all of the T1D patients with and without DN among Swedish population, the $\mathrm{C}$ allele frequency was $7.1 \%$, which was significantly higher than that in all American T1D patients $\left(4.0 \% ; P=0.006\right.$ and $P_{\mathrm{c}}=0.012$ with Bonferroni correction for multiple comparisons). Analyses of allelic association indicated that the $\mathrm{C}$ allele frequencies between Swedish female T1D patients with and without DN were different (10.2 vs $4.2 \% ; P=0.011$ and $P_{\mathrm{c}}=0.022$ with Bonferroni correction). A similar comparison analysis between Swedish male T1D patients with and without $\mathrm{DN}$ was done; however, the $\mathrm{C}$ allele frequencies were found to be similar ( 5.3 and $6.0 \% ; P=0.766)$.

Table 2 demonstrated the genotype distribution and the $\mathrm{C}$ allele frequencies of male and female American T1D patients with and without DN. In the collected subjects of GoKinD, $\sim 8 \%$ of total subjects were Americans of Black, Asian, Hispanic, or Indian descents.

Table 2 Genotype distributions and allele frequencies of Leu7Pro polymorphism in the neuropeptide $Y$ gene.

\begin{tabular}{|c|c|c|c|c|c|c|}
\hline & \multicolumn{3}{|c|}{ Genotypes (\%) } & \multirow[b]{2}{*}{$P$ value } & \multirow[b]{2}{*}{ MAF (\%) C } & \multirow[b]{2}{*}{$P$ value } \\
\hline & TT & TC & $\mathrm{CC}$ & & & \\
\hline \multicolumn{7}{|c|}{$\begin{array}{l}\text { A. Swedish population } \\
\text { T1D without DN }\end{array}$} \\
\hline All & $225(90.4)$ & $23(9.2)$ & $1(0.4)$ & & 5.0 & \\
\hline Male & 104 (88.9) & $12(10.3)$ & $1(0.8)$ & & 6.0 & \\
\hline Female & $121(91.7)$ & $11(8.3)$ & 0 & & 4.2 & \\
\hline \multicolumn{7}{|c|}{ T1D with DN } \\
\hline All & $148(85.1)$ & $24(13.8)$ & $2(1.1)$ & 0.218 & 8.1 & 0.074 \\
\hline Male & $68(89.5)$ & $8(10.5)$ & 0 & 0.721 & 5.3 & 0.766 \\
\hline Female & $80(81.6)$ & $16(16.3)$ & $2(2.1)$ & 0.041 & 10.2 & $0.011^{\mathrm{a}}$ \\
\hline \multicolumn{7}{|c|}{ B. GoKinD population } \\
\hline All & $552(0.926)$ & $44(0.074)$ & 0 & & 3.7 & \\
\hline Male & $224(0.933)$ & $16(0.067)$ & 0 & & 3.3 & \\
\hline Female & $328(0.921)$ & $28(0.079)$ & 0 & & 3.9 & \\
\hline \multicolumn{7}{|c|}{ T1D with DN } \\
\hline All & $527(0.916)$ & $47(0.082)$ & $1(0.002)$ & 0.522 & 4.3 & 0.480 \\
\hline Male & $283(0.910)$ & $28(0.090)$ & 0 & 0.316 & 4.5 & 0.326 \\
\hline Female & $244(0.924)$ & $19(0.072)$ & $1(0.004)$ & 0.487 & 4.0 & 0.968 \\
\hline
\end{tabular}

T1D, type 1 diabetes; DN, diabetic nephropathy; $P$ values, T1D patients with DN versus T1D patients without DN; MAF, minor allele frequency. ${ }^{\mathrm{a}} \mathrm{OR}(95 \% \mathrm{Cl})=2.614(1.249-5.467) ; P_{\mathrm{c}}$ value with Bonferroni correction was 0.022 . 
In order to avoid the error caused by the subjects from different races, those patients were excluded from the analyses. Analyses between T1D patients with and without DN, who were descents of European Caucasians in the American population, were conducted. Data indicated that male and female T1D patients with DN had similar frequencies of the $\mathrm{C}$ allele in NPY Leu/Pro polymorphism $(4.5$ and $4.0 \%)$ in comparison with the male and female T1D patients without DN (3.3 and $3.9 \% ; P=0.326$ and 0.968 respectively).

We further performed a multivariate logistic regression analysis to predict the susceptibility to DN. Table 3 shows that Leu7Pro polymorphism was strongly associated with DN in Swedish female T1D patients $(P=0.039$, $\mathrm{OR}=3.379,95 \% \mathrm{CI}: 1.061-10.768)$, when variables of duration, HbA1c, systolic blood pressure (SBP), and diastolic blood pressure (DBP) were included in the model. Since SBP and DBP between the patients with DN and without DN in both male and female were found to be significantly different, the similar test for Swedish male T1D patients with and without DN was also performed. No statistically significant association with DN in Swedish male T1D patients was detected (data not shown).

\section{Discussion}

We have conducted a genetic association study of NPY Leu7Pro polymorphism in T1D patients with and without DN among Swedish and American populations. We found the $\mathrm{C}$ allele frequency of this polymorphism in T1D patients with and without DN among Swedish population was higher than that in American population. Furthermore, we found that polymorphism was significantly associated with DN in Swedish female T1D patients.

The previous studies have demonstrated that the $\mathrm{C}$ allele of Leu7Pro polymorphism showed a decreasing frequency with the geographical distribution from north to south gradient. The highest $\mathrm{C}$ allele frequency was found in Finnish and the second highest in Swedish (13, 18-20). Furthermore, Pettersson-Fernholm et al. reported that Leu7Pro polymorphism in Finnish T1D patients had the $\mathrm{C}$ allele frequency of $7.5 \%$, and the $\mathrm{C}$ allele had the risk susceptibility for DN and CHD in female but not in male patients with T1D (24). Results from the present study indicate that the $\mathrm{C}$ allele frequency of Leu7Pro polymorphism in Swedish T1D

Table 3 Multivariate logistic regression analysis in Swedish female type 1 diabetes patients with diabetic nephropathy.

\begin{tabular}{lrrrr}
\hline & Estimate & s.E.M. & $\boldsymbol{P}$ value & OR $(95 \% \mathrm{Cl})$ \\
\hline Leu7Pro TT & 1.017 & 0.419 & 0.039 & $\begin{array}{c}3.379 \\
(1.061-10.768)\end{array}$ \\
$\quad$ versus TC & & & & \\
$\quad+$ CC & & & & \\
HbA1c & -0.037 & 0.054 & 0.498 & \\
SBP $(\mathrm{mmHg})$ & 0.010 & 0.011 & 0.370 & \\
DBP $(\mathrm{mmHg})$ & -0.007 & 0.017 & 0.681 & \\
\hline
\end{tabular}

Test was performed by co comparison of Swedish female T1D patients without DN.

www.eje-online.org patients is $6.3 \%$, which is slightly lower than that in Finnish T1D patients (24) but significantly higher in comparison with American T1D patients (4.0\%). Importantly, we found that the $\mathrm{C}$ allele of Leu7Pro polymorphism was significantly associated with female T1D patients with DN among Swedish population. The association remains significant after Bonferroni correction for multiple comparisons. Clinical evidence demonstrates that female T1D patients with DN have reduced circulating levels of estradiol and have imbalance in the expression of estrogen receptor subtypes (26). The female T1D patients who develop microalbuminuria are younger than the corresponding male subjects $(27,28)$. In the recent years, we have used positional candidate gene approach to detect the susceptibility genes in DN. In addition to the present study, we have found that several candidate genes, for instance, adiponectin, confer the genetic susceptibility in female T1D patients with DN (Zhang et al. unpublished data). Therefore, we suggest that there are gender-specific effects of the genetic risk for DN. However, T1D and DN are complex diseases. To dissect the complexity and fully explain the mechanism behind, it is necessary to investigate more genes and also to elucidate the biological basis of genegender interactions in the etiology of these diseases.

We analyzed the data for the subjects in Swedish and American GoKinD populations separately in order to avoid a type 2 error caused by different genetic backgrounds from different ethnic groups. In the GoKinD population, all studied patients are highly selected from American T1D population, and they are descents of European Caucasians but may not be from Sweden or Finland. We found that the frequencies of allele $\mathrm{C}$ in T1D patients with and without DN were low, and no significant association between Leu7Pro polymorphism and DN was detectable. Moreover, 34.7\% of the patients had ESRD. We attempted to detect the association between Leu7Pro polymorphism and ESRD, and no statistically significant results were found.

Taken together the present study and previous reports, we thus conclude that NPY Leu7Pro polymorphism distributes with higher $\mathrm{C}$ allele frequency in Swedish population. This polymorphism confers the susceptibility to the development of DN in Swedish female T1D patients, and its susceptibility may interact with environmental factors in the northern geographical area. Question concerning gender specificity related to genetic influence has been taken into our consideration.

\section{Acknowledgements}

The authors wish to thank all subjects for participating in the present study. The Genetics of Kidneys in Diabetes (GoKinD) Study sample collection is supported by the Juvenile Diabetes Research Foundation in collaboration with the Joslin Diabetes Center and George Washington University and the United States Centers for Diabetes Control and Prevention. The present work was supported 
by the Novo Nordic Consortium, Swedish Research Council, Novo Nordisk Scandinavia, Glaxo Smith Kline, Vetenskapligt arbete inom diabetologi foundation, Loo and Hans Osterman foundation, and Swedish Diabetes Association. Jun Ma is a $\mathrm{PhD}$ student at KI, but originally from Weifang Medical University, People's Republic of China.

\section{References}

1 Rippin JD, Patel A \& Bain SC. Genetics of diabetic nephropathy. Best Practice and Research. Clinical Endocrinology and Metabolism $200115345-358$.

2 Jamal H, Jones PM, Byrne J, Suda K, Ghatei MA, Kanse SM \& Bloom SR. Peptide contents of neuropeptide Y, vasoactive intestinal polypeptide, and beta-calcitonin gene-related peptide and their messenger ribonucleic acids after dexamethasone treatment in the isolated rat islets of Langerhans. Endocrinology $19911293372-3380$.

3 Wang ZL, Bennet WM, Wang RM, Ghatei MA \& Bloom SR. Evidence of a paracrine role of neuropeptide- $Y$ in the regulation of insulin release from pancreatic islets of normal and dexamethasone-treated rats. Endocrinology 1994135 200-206.

4 Bennet WM, Wang ZL, Jones PM, Wang RM, James RF, London NJ, Ghatei MA \& Bloom SR. Presence of neuropeptide Y and its messenger ribonucleic acid in human islets: evidence for a possible paracrine role. Journal of Clinical Endocrinology and Metabolism $1996812117-2120$.

5 Myrsen-Axcrona U, Karlsson S, Sundler F \& Ahren B. Dexamethasone induces neuropeptide Y (NPY) expression and impairs insulin release in the insulin-producing cell line RINm5F. Journal of Biological Chemistry 1997272 10790-10796.

6 Petterson M, Ahren B, Lundquist I, Bottcher G \& Sundler F. Neuropeptide Y: intrapancreatic neuronal localization and effects on insulin secretion in the mouse. Cell and Tissue Research 1987 248 43-48.

7 Skoglund G, Gross RA, Bertrand GR, Ahren B \& LoubatieresMariani MM. Comparison of effects of neuropeptide $\mathrm{Y}$ and norepinephrine on insulin secretion and vascular resistance in perfused rat pancreas. Diabetes 199140 660-665.

8 Bischoff A \& Michel MC. Renal effects of neuropeptide Y. Pflugers Archiv $1998 \mathbf{4 3 5} 443-453$.

9 Playford RJ, Mehta S, Upton P, Rentch R, Moss S, Calam J, Bloom S, Payne N, Ghatei M, Edwards R \& Unwin R. Effect of peptide YY on human renal function. American Journal of Physiology 1995268 F754-F759.

10 Satoh C, Satoh F, Takahashi K, Murakami O, Sone M, Totsune K, Yabe T, Ohneda M, Fukuda M, Sugimura K, Ogawa S, Nagakubo H, Sato T \& Mouri T. Elevated plasma immunoreactive neuropeptide $\mathrm{Y}$ concentrations and its increased urinary excretion in patients with advanced diabetic nephropathy. Endocrine Journal 199946 139-146.

11 Gozali M, Pavia JM \& Morris MJ. Involvement of neuropeptide Y in glucose sensing in the dorsal hypothalamus of streptozotocin diabetic rats - in vitro and in vivo studies of transmitter release. Diabetologia 200245 1332-1339.

12 Morris MJ \& Pavia JM. Increased endogenous noradrenaline and neuropeptide Y release from the hypothalamus of streptozotocin diabetic rats. Brain Research 20041006 100-106.

13 Karvonen MK, Pesonen U, Koulu M, Niskanen L, Laakso M, Rissanen A, Dekker JM, Hart LM, Valve R \& Uusitupa MI. Association of a leucine(7)-to-proline(7) polymorphism in the signal peptide of neuropeptide $\mathrm{Y}$ with high serum cholesterol and LDL cholesterol levels. Nature Medicine 19984 1434-1437.

14 Kallio J, Pesonen U, Karvonen MK, Kojima M, Hosoda H, Kangawa K \& Koulu M. Enhanced exercise-induced GH secretion in subjects with Pro7 substitution in the prepro-NPY. Journal of Clinical Endocrinology and Metabolism 200186 5348-5352.
15 Pihlajamaki J, Karhapaa P, Vauhkonen I, Kekalainen P, Kareinen A, Viitanen L, Pesonen U, Kallio J, Uusitupa M \& Laakso M. The Leu 7Pro polymorphism of the neuropeptide $\mathrm{Y}$ gene regulates free fatty acid metabolism. Metabolism $2003 \mathbf{5 2} 643-646$.

16 Mattevi VS, Zembrzushi VM \& Hutz MH. Association analysis of gene involved in the leptin-signaling pathway with obesity in Brazil. International Journal of Obesity and Related Metabolic Disorders 200226 1179-1185.

17 Karvonen MK, Ruottinen S, Koulu M, Pesonen U, Niinikoski H, RaskNissila L, Simell O \& Ronnemaa T. Nutrient intake, weight, and Leu7Pro polymorphism in prepro-neuropeptide $\mathrm{Y}$ in children. Journal of Clinical Endocrinology and Metabolism 200691 4664-4668.

18 Ding B, Kull B, Liu Z, Mottagui-Tabar S, Thonberg H, Gu HF, Brookes AJ, Grundemar L, Karlsson C, Hamsten A, Arner P, Ostenson CG, Efendic S, Monne M, von Heijne G, Eriksson P \& Wahlestedt C. Human neuropeptide Y signal peptide gain-of-function polymorphism is associated with increased body mass index: possible mode of function. Regulatory Peptides 2005127 45-53.

19 Ding B. Distribution of the NPY 1128C allele frequency in different populations. Journal of Neural Transmission 2003110 1199-1204.

20 Nordman S, Ding B, Ostenson CG, Karvestedt L, Brismar K, Efendic S \& Gu HF. Leu7Pro polymorphism in the neuropeptide Y (NPY) gene is associated with impaired glucose tolerance and type 2 diabetes in Swedish men. Experimental and Clinical Endocrinology and Diabetes $2005113282-287$.

21 Koulu M, Movafagh S, Tuohimaa J, Jaakkola U, Kallio J, Pesonen U, Geng Y, Karvonen MK, Vainio-Jylha E, Pollonen M, KaipioSalmi K, Seppala H, Lee EW, Higgins RD \& Zukowska Z. Neuropeptide Y and Y2-receptor are involved in development of diabetic retinopathy and retinal neovascularization. Annals of Medicine 200436 232-240.

22 Niskanen L, Voutilainen-Kaunisto R, Terasvirta M, Karvonen MK, Valve R, Pesonen U, Laakso M, Uusitupa MI \& Koulu M. Leucine 7 to proline 7 polymorphism in the neuropeptide y gene is associated with retinopathy in type 2 diabetes. Experimental and Clinical Endocrinology and Diabetes 2000108 235-236.

23 Niskanen L, Karvonen MK, Valve R, Uusitupa MI, Tammi A, Viikari J, Simell O \& Ronnemaa T. Leucine 7 to proline 7 polymorphism in the neuropeptide $\mathrm{Y}$ gene is associated with enhanced carotid atherosclerosis in elderly patients with type 2 diabetes and control subjects. Journal of Clinical Endocrinology and Metabolism 200085 2266-2269.

24 Pettersson-Fernholm K, Karvonen MK, Kallio J, Forsblom CM, Koulu M, Pesonen U, Fagerudd JA, Groop PH \& FinnDiane Study Group. Leucine 7 to proline 7 polymorphism in the preproneuropeptide $\mathrm{Y}$ is associated with proteinuria, coronary heart disease, and glycemic control in type 1 diabetic patients. Diabetes Care 200427 503-509.

25 World Health Organization. Diabetes mellitus Report of a WHO Study Group. Technical Report Series 727 Geneva: WHO, 1985.

26 Mueller PW, Rogus JJ, Cleary PA, Zhao Y, Smiles AM, Steffes MW, Bucksa J, Gibson TB, Cordovado SK, Krolewski AS, Nierras CR \& Warram JH. Genetics of kidneys in diabetes (GoKinD) study: a genetics collection available for identifying genetic susceptibility factors for diabetic nephropathy in type 1 diabetes. Journal of the American Society of Nephrology 200617 1782-1790.

27 Wells CC, Riazi S, Mankhey RW, Bhatti F, Ecelbarger C \& Maric C. Diabetic nephropathy is associated with decreased circulating estradiol levels and imbalance in the expression of renal estrogen receptors. Gender Medicine $20052227-237$.

28 Schultz CJ, Gale EAM, Konopelska-Bahu T, Neil A, Dalton RN, Dunger DB, Carroll TA \& Stratton I. Microalbuminuria prevalence varies with age, sex, and puberty in children with type 1 diabetes followed from diagnosis in a longitudinal study. Diabetes Care 199922 495-501.

Received 14 August 2007

Accepted 29 August 2007 